Supplement of Biogeosciences, 16, 2949-2960, 2019 https://doi.org/10.5194/bg-16-2949-2019-supplement (C) Author(s) 2019. This work is distributed under the Creative Commons Attribution 4.0 License.

(c) (1)

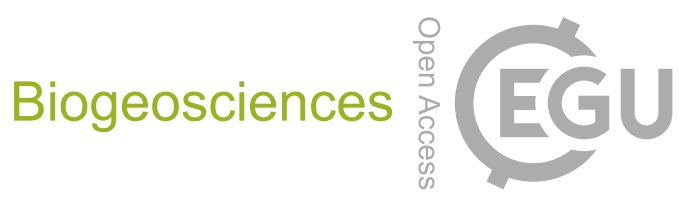

Supplement of

\title{
Ideas and perspectives: Synergies from co-deployment of negative emission technologies
}

Thorben Amann and Jens Hartmann

Correspondence to: Thorben Amann (science@thorbenamann.de)

The copyright of individual parts of the supplement might differ from the CC BY 4.0 License. 
S1. Development of global potassium/potash resources ............................................ 2

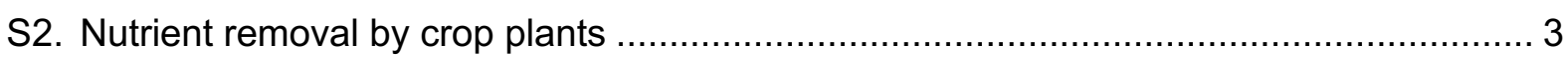

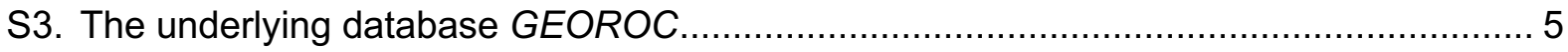

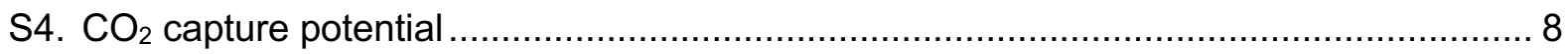

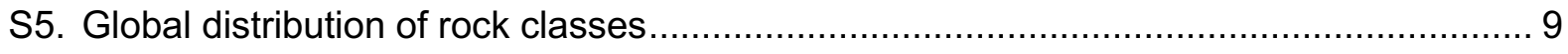

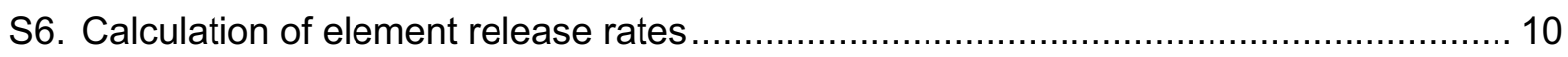

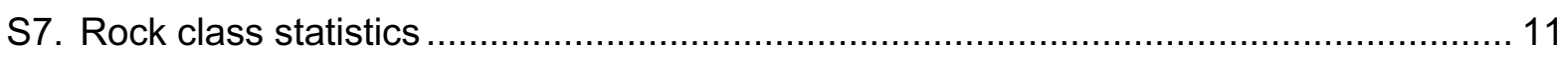

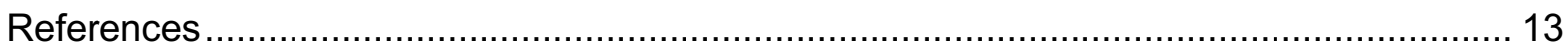




\section{S1. Development of global potassium/potash resources}

Manning (2015) described the development of global potassium resources. Here we took the underlying data to recreate the figure, extended by the two most recent years as available (Fig. S1-1).

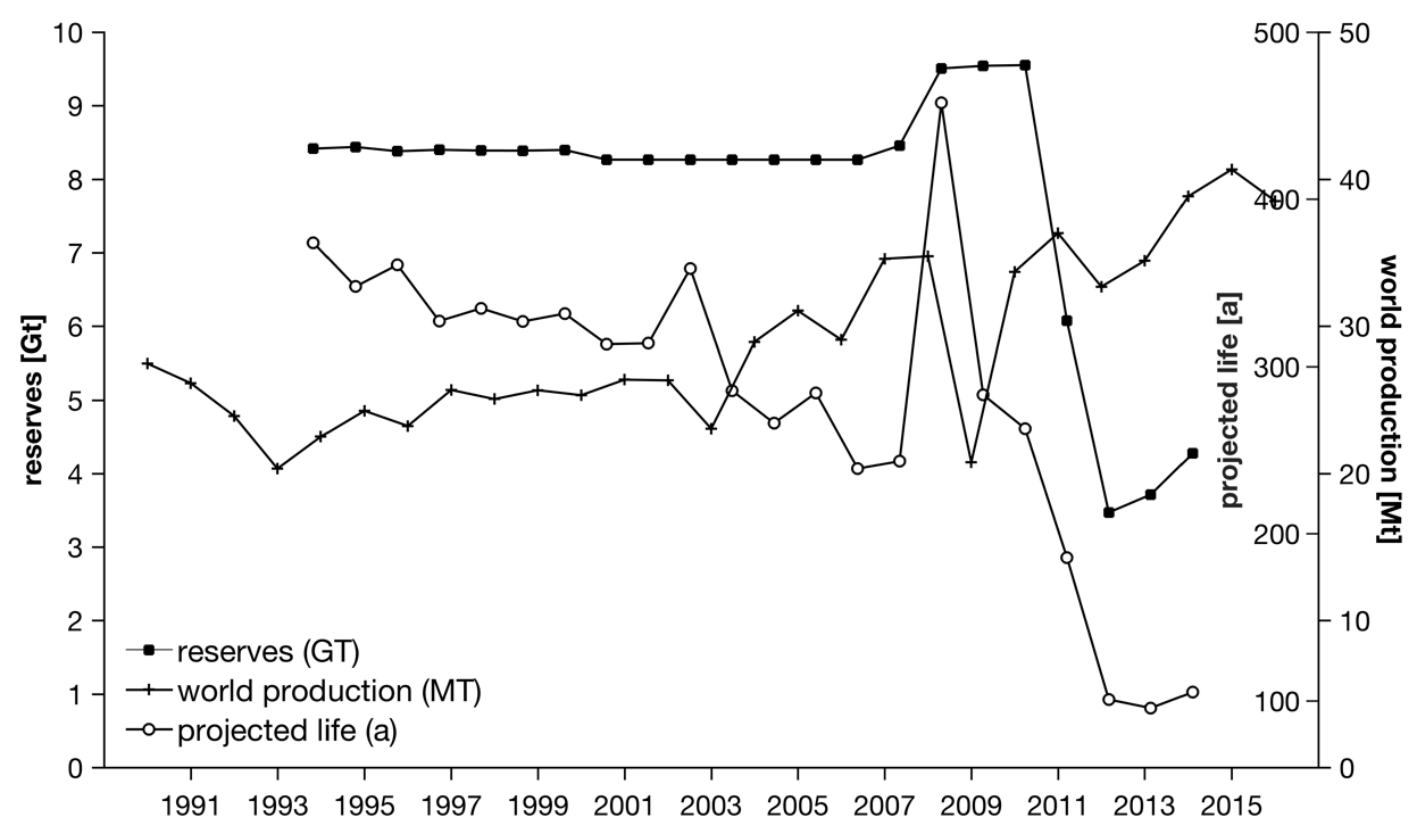

Fig. S1-1 Update of data from Manning (2015), extended by the two most recent years. Data from Jasinski (2017), accessed through https://minerals.usgs.gov/minerals/pubs/commodity/potash/ on 2017-06-13. 


\section{S2. Nutrient removal by crop plants}

In addition to the data for Miscanthus shown in the main text, we provide here some exemplary additional data on crop plants that would potentially benefit from rock released nutrients (Fig. S2-1). The historical development of crop yields shows that the nutrient extraction of major crops increased steeply in the past (Fig. S2-2) indicating the need for a sustainable long-term nutrient cycle management, not only for new energy plants.

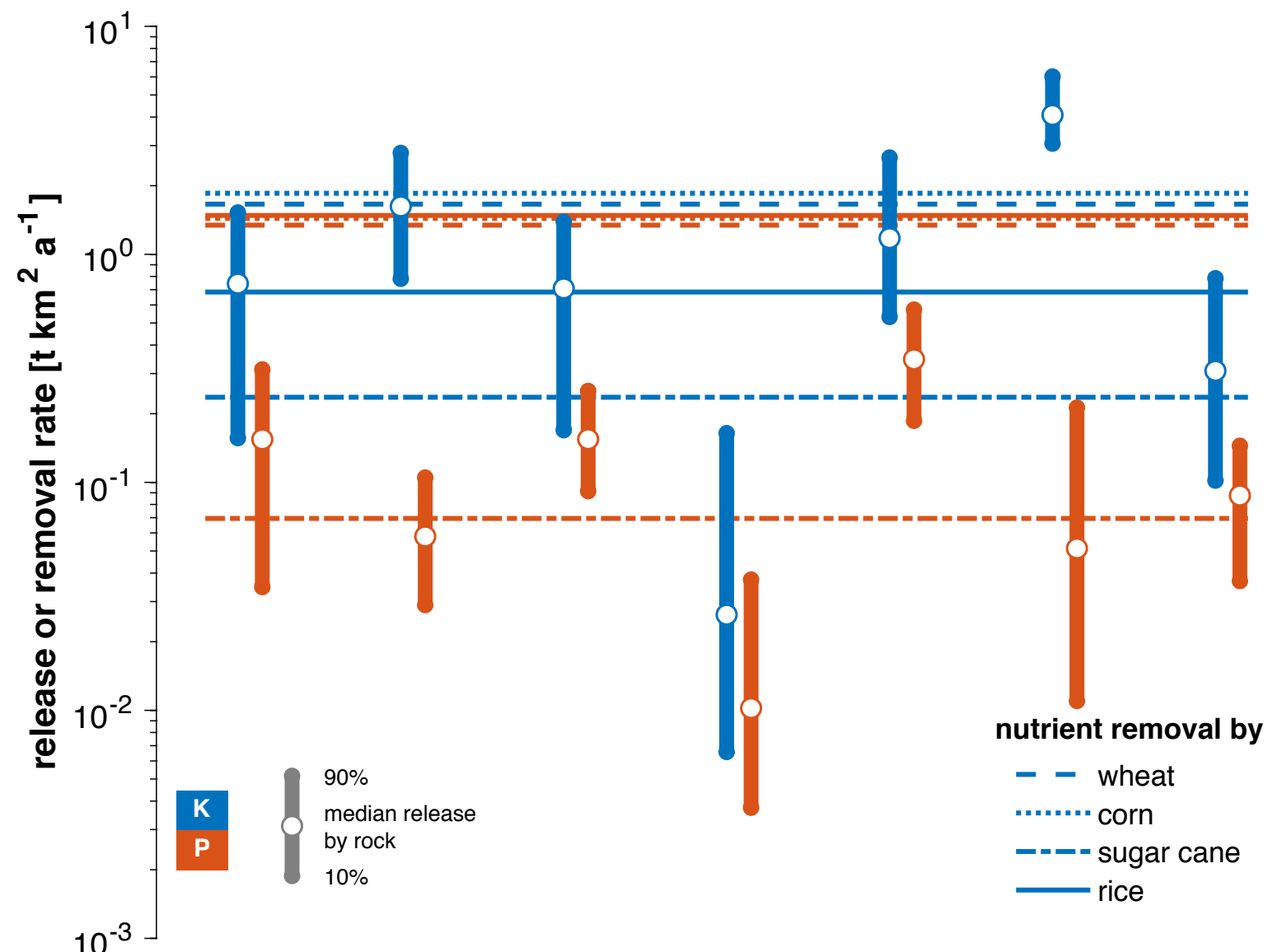

Phonolite Dacite Tholeiite Basalt Nephelinite Kimberlite Komatiite

Fig. S2-1 Weathering release rates (circles; bars as variability indicator) of $P$ and $K$ from a few selected volcanic rocks (assuming their full dissolution during a natural weathering scenario based on subtropical Japanese catchments (cf. S6)) in comparison with the average nutrient removal by harvesting the crops (dashed lines), i.e. the actual nutrient removal from the cropland, whereas residues are considered to remain on the land. 

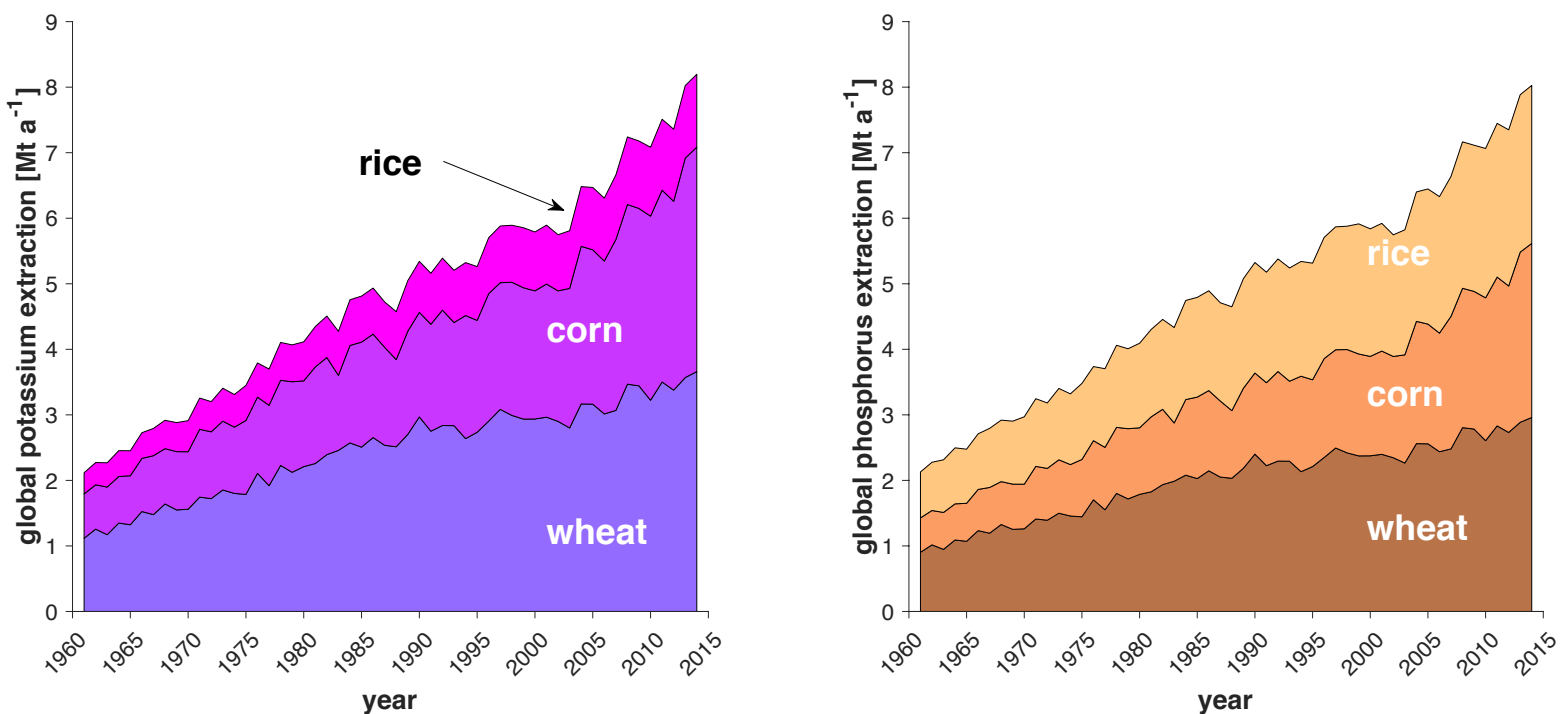

Fig. S2-2 The total annual global removal of $K$ and $P$ by harvest for three major crops over time. Data taken from FAOSTAT (2017).

The removal of nutrients was calculated based on published data on crop yields (Tab. S2-1) and average contents of $\mathrm{P}$ and $\mathrm{K}$ from the literature in selected crop types (Tab. S2-2), considering only the harvestable material (mainly grains, for sugar cane: stalks, for Miscanthus: all harvestable parts):

$$
\text { Nutrient removal }=\frac{\text { Element content }(\%)}{100} \times \text { Yield }
$$

Tab. S2-1 Global average yields of selected crop plants.

\begin{tabular}{|c|c|c|}
\hline Plant & Yield in 2014 (t km²) & Reference \\
\hline Barley & 292.33 & FAOSTAT (2017) \\
\hline Corn & 561.57 & FAOSTAT (2017) \\
\hline Rice & 455.69 & FAOSTAT (2017) \\
\hline Soy beans & 260.76 & FAOSTAT (2017) \\
\hline Sugar cane & 6946.6 & FAOSTAT (2017) \\
\hline \multirow[t]{2}{*}{ Wheat } & 330.74 & FAOSTAT (2017) \\
\hline & Observed yield $\min / \max \left(\mathrm{t} \mathrm{km}^{-2}\right)$ & \\
\hline Miscanthus & $40 / 4400$ & Brosse et al. (2012) \\
\hline
\end{tabular}

Tab. S2-2 Potassium and phosphorus contents in harvestable parts of plants (grains, stalks), in case of Miscanthus, the value refers to all harvestable parts.

\begin{tabular}{|c|c|c|c|}
\hline \multirow{2}{*}{ Plant } & K & $P$ & \multirow{2}{*}{ Reference } \\
\hline & \multicolumn{2}{|c|}{ (\% of biomass) } & \\
\hline Barley & 0.009 & 0.01 & Erbs et al. (2010) \\
\hline Corn & 0.33 & 0.256 & Belitz (2009) \\
\hline Rice & 0.15 & 0.325 & Belitz (2009) \\
\hline Soy beans & 2.05 & 0.67 & Batal et al. (2010) \\
\hline Sugar cane & 0.0034 & 0.001 & Fageria (1991) \\
\hline Wheat & 0.502 & 0.406 & Belitz (2009) \\
\hline Miscanthus min & 0.11 & 0.04 & Brosse et al. (2012) \\
\hline Miscanthus max & 1.58 & 0.11 & Brosse et al. (2012) \\
\hline
\end{tabular}




\section{S3. The underlying database GEOROC}

The GEOROC data was provided as Microsoft Access database files by the maintainer of http://georoc.mpch-mainz.gwdg.de/georoc/ on 2018-04-11. Files were converted and stored in a MySQL database (v8.0.12) for further queries. The query output was loaded into the software MATLAB (R2018b) to create statistics and figures. Below, a rough rundown of the preparation is given. Fig. S3-1 provides an overview of the geographic distribution of samples included in the calculations.

1. Select the data, that should be used, from the entirety of the database. This creates a table, that has all the chemical data in it, plus some additional information to classify the material and to exclude certain samples (subaquatic, not whole rock...).

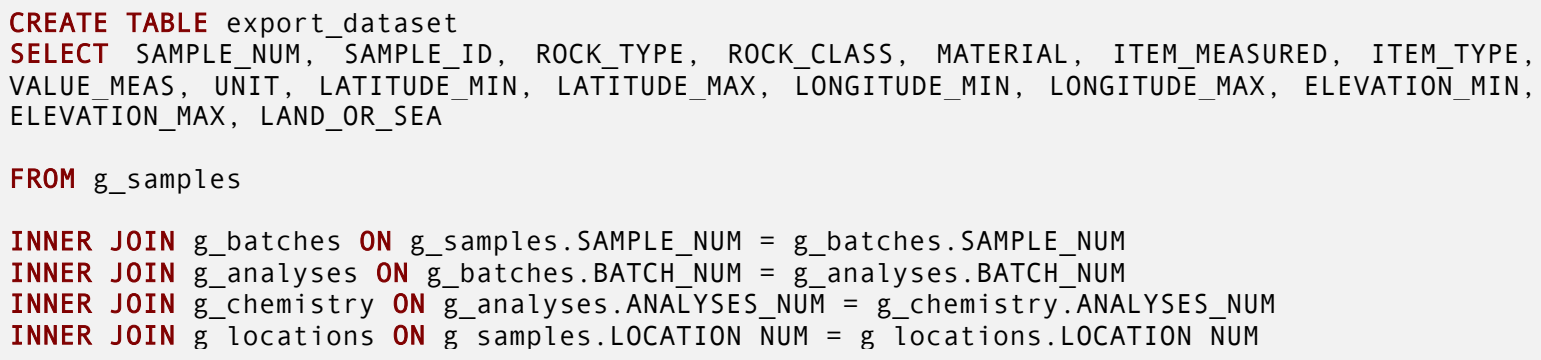

2. The relational style of the data had to be converted to a linear list of samples, each with data on selected parameters $\left(\mathrm{SiO}_{2}\right.$, etc.). While doing this, a column was introduced, classifying the samples by $\mathrm{SiO}_{2}$ content into

- Ultrabasic rocks, containing < $45 \mathrm{wt} \% \mathrm{SiO}_{2}$, called pu, vu (p: plutonic; v: volcanic)

- Basic rocks, containing 45 - $52 \mathrm{wt} \% \mathrm{SiO}_{2}$, called pb, vb

- Intermediate rocks, containing $52.0001-63 \mathrm{wt} \% \mathrm{SiO}_{2}$, called pi, vi

- Acid rocks, containing $>63 \mathrm{wt} \% \mathrm{SiO}_{2}$, called pa, va

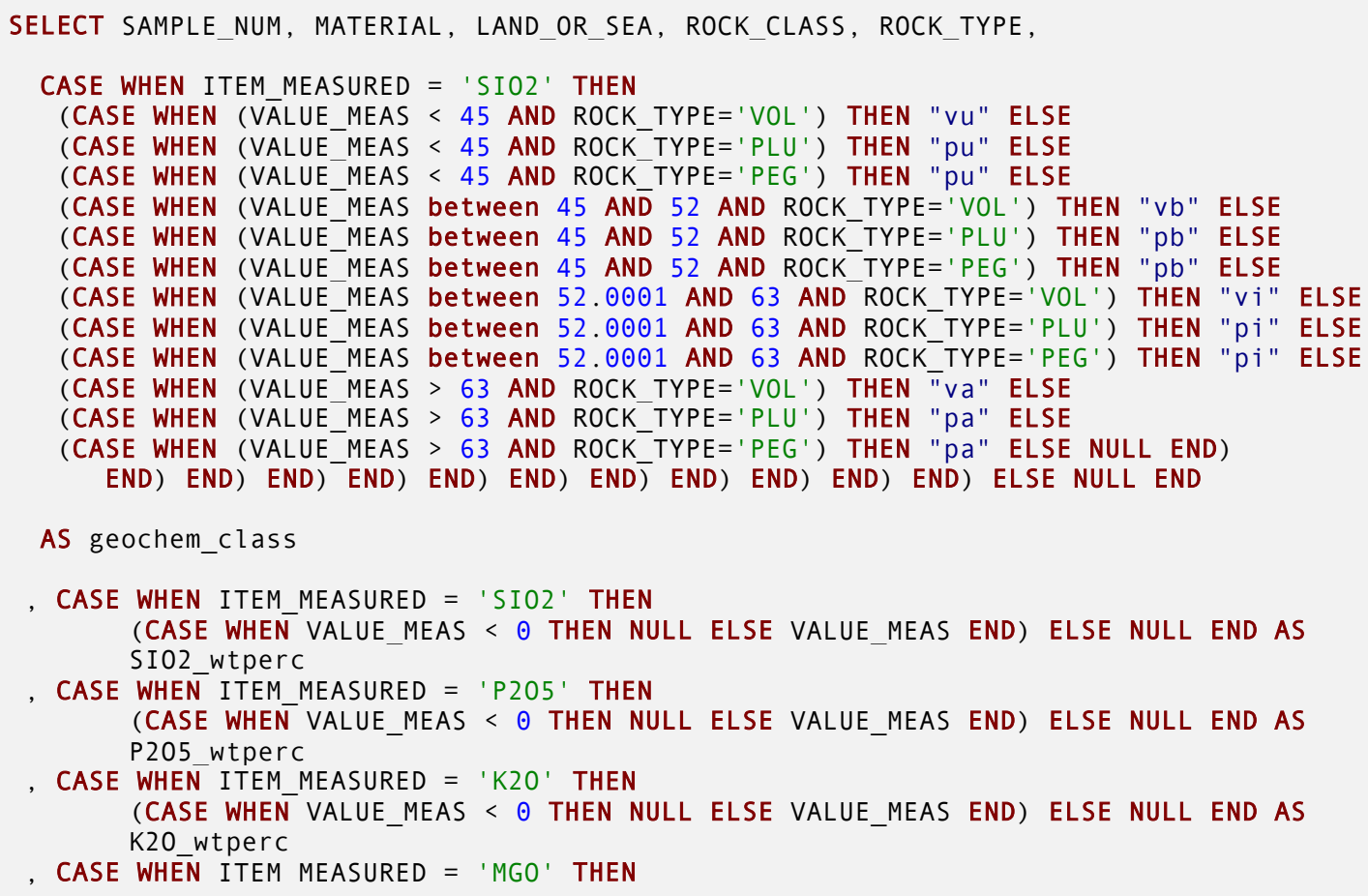


(CASE WHEN VALUE_MEAS < $\odot$ THEN NULL ELSE VALUE_MEAS END) ELSE NULL END AS MGO_wtperc

CASE WHEN ITEM MEASURED $=$ 'CAO' THEN

(CASE WHEN VALUE_MEAS < $\odot$ THEN NULL ELSE VALUE_MEAS END) ELSE NULL END AS CAO_wtperC

CASE WHEN ITEM MEASURED $=$ 'NA20' THEN

(CASE WHEN VALUE_MEAS < 0 THEN NULL ELSE VALUE_MEAS END) ELSE NULL END AS NA20 wtperc

CASE WHEN ITEM MEASURED $=$ 'NIO' THEN (CASE WHEN VALUE_MEAS < $\odot$ THEN NULL ELSE VALUE_MEAS END) ELSE NULL END AS NIO wtperC

CASE WHEN ITEM MEASURED $={ }^{\prime}$ CR203' THEN (CASE WHEN VALUE_MEAS < 0 THEN NULL ELSE VALUE_MEAS END) ELSE NULL END AS CR203 wtperC

CASE WHEN ITEM_MEASURED $=$ 'SI ' THEN (CASE WHEN VALUE_MEAS < $\odot$ THEN NULL ELSE VALUE_MEAS END) ELSE NULL END AS SI PPM

CASE WHEN ITEM_MEASURED $=$ ' $K$ ' THEN (CASE WHEN VALUE_MEAS < $\odot$ THEN NULL ELSE VALUE_MEAS END) ELSE NULL END AS K_PPM

CASE WHEN ITEM MEASURED $=$ 'CA' THEN (CASE WHEN VALUE MEAS < $\odot$ THEN NULL ELSE VALUE MEAS END) ELSE NULL END AS CA_PPM

CASE WHEN ITEM MEASURED = 'MG' THEN (CASE WHEN VALUE MEAS < $\odot$ THEN NULL ELSE VALUE MEAS END) ELSE NULL END AS MG_PPM

CASE WHEN ITEM MEASURED = 'NA' THEN (CASE WHEN VALUE MEAS < $\odot$ THEN NULL ELSE VALUE MEAS END) ELSE NULL END AS NA_PPM

CASE WHEN ITEM MEASURED $=$ ' $P$ ' THEN

(CASE WHEN VALUE_MEAS < $\odot$ THEN NULL ELSE VALUE_MEAS END) ELSE NULL END AS P_PPM

CASE WHEN ITEM MEASURED = 'NI' THEN

(CASE WHEN VALUE_MEAS < $\odot$ THEN NULL ELSE VALUE_MEAS END) ELSE NULL END AS NI_PPM

CASE WHEN ITEM MEASURED $=$ 'CR' THEN (CASE WHEN VALUE_MEAS < $\odot$ THEN NULL ELSE VALUE_MEAS END) ELSE NULL END AS CR_PPM

FROM export_dataset

WHERE (ITEM MEASURED IN

('SIO2', 'K20', 'P205', 'CAO', 'MGO', 'NA20', 'NIO', 'CR203', 'SI', 'K', 'CA', 'MG', 'NA', 'P', 'NI', 'CR'))

AND MATERIAL $=$ 'WR'

AND (ROCK_TYPE $=$ 'VOL' OR ROCK_TYPE $=$ 'PLU' OR ROCK_TYPE $=$ 'PEG')

AND LAND_OR_SEA $=$ "SAE"

GROUP BY SAMPLE_NUM

3. A table was exported from MySQL and imported to MATLAB. The data contained $\mathrm{SiO}_{2}$, $\mathrm{K} 2 \mathrm{O}, \mathrm{P}_{2} \mathrm{O}_{5}, \mathrm{NiO}, \mathrm{Cr}_{2} \mathrm{O}_{3}, \mathrm{Si}, \mathrm{K}, \mathrm{P}, \mathrm{Ni}, \mathrm{Cr}$.

It was narrowed down to contain only rock samples of plutonic, pegmatitic, and volcanic nature. Only under subaerial conditions and only analyses were selected where the whole rock was analysed. As there were very few data points with negative values, the code was adapted not to include those values. 


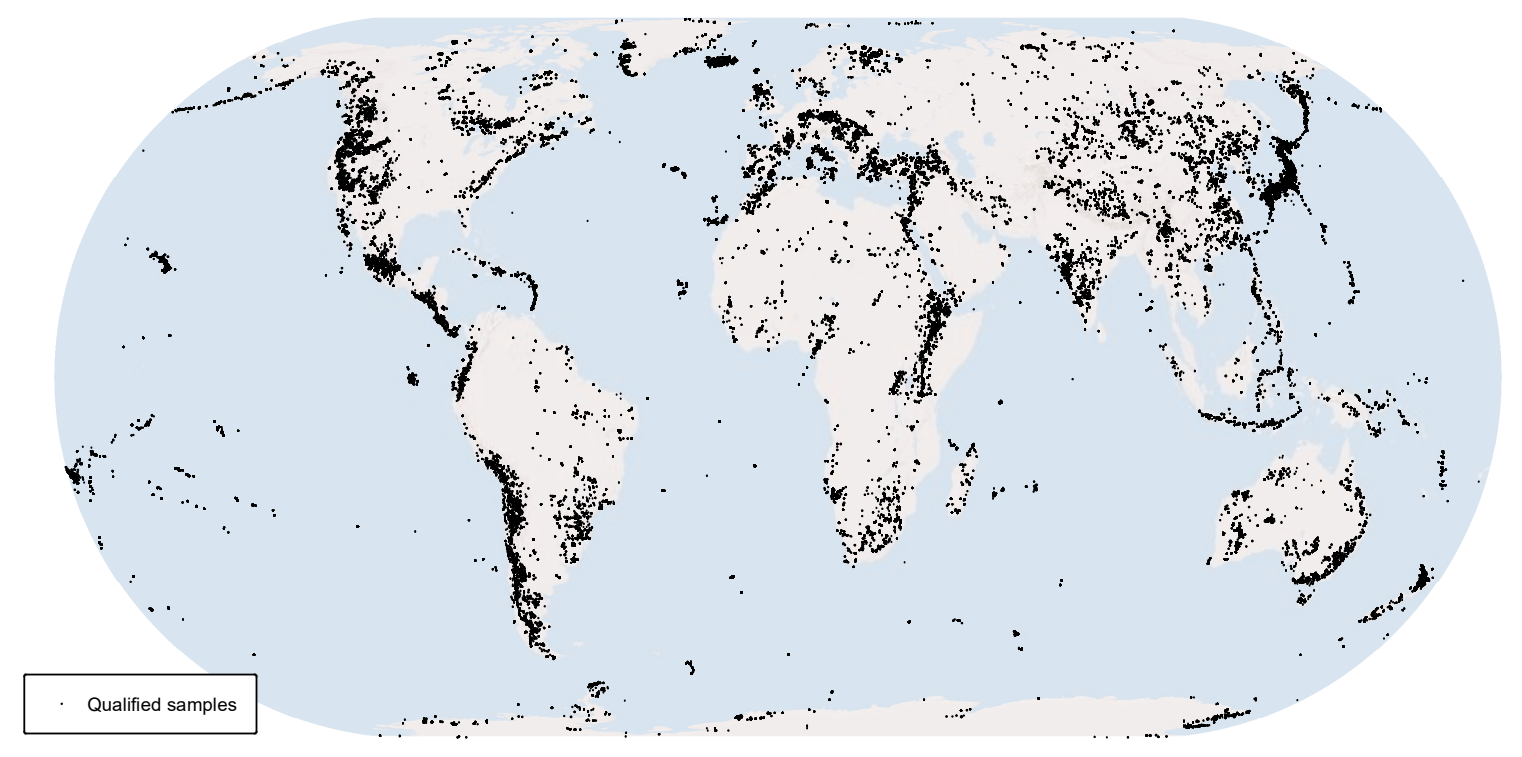

Fig. S3-1 Global distribution of qualified samples in the GEOROC database. 


\section{S4. $\quad \mathrm{CO}_{2}$ capture potential}

The ability to sequester atmospheric $\mathrm{CO}_{2}$ is rock specific and depends on the cations that can be released during hydrolysis. It is defined as the carbon dioxide removal potential $\mathrm{R}_{\mathrm{CO} 2}$ in tonnes $\mathrm{CO}_{2}$ per tonne of rock:

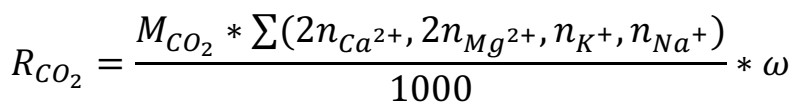

$n=$ molar amount of cation $\mathrm{x}, M_{\mathrm{CO} 2}=$ molar mass of $\mathrm{CO}_{2}$, and $\omega=0.85$, factoring in seawater equilibration processes (cf. Fig. 1 in Renforth et al., 2013). They considered only divalent cations, where two charges bind about 1.7 moles $\mathrm{CO}_{2}(\sim 15 \%$ less, thus factor 0.85). Fig. 2 in the main text shows only selected rock types. Fig. S3-1 provides an overview over $\mathrm{R}_{\mathrm{CO} 2}$ values of all volcanic rock types differentiated in the GEOROC database. Plutonic rock types were omitted here, since the amount of data on particular rock types in the provided data is comparably low. Additionally, the data preprocessing to get "clean" rock types, is very work intensive, which is not justified in the context of this publication.

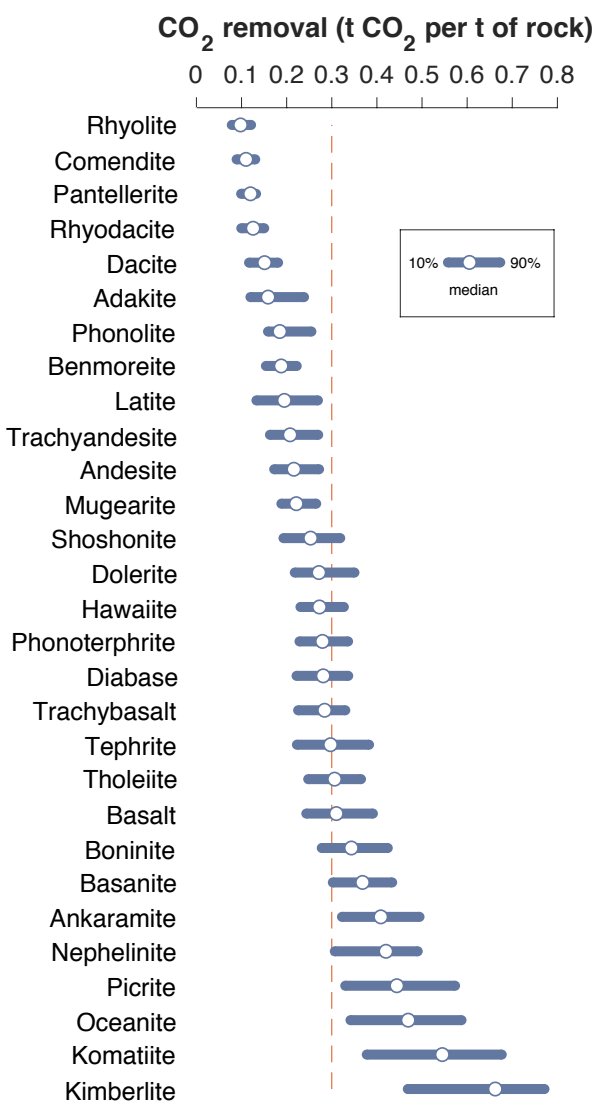

Fig. S 4-1 Calculated efficiency of $\mathrm{CO}_{2}$ removal $\left(R_{\mathrm{CO} 2}\right)$ for all volcanic rock types given in the GEOROC database. The dashed line is the pessimistic $\mathrm{CO}_{2}$ emission during production of rock flour from Moosdorf et al. (2014), but would be lower fossil energy provides were provided by renewables for the processing. 


\section{S5. Global distribution of rock classes}

The distribution of rock classes gives a rough overview of where to find the respective rock class. This overview is based on data from the global lithological map database GLiM (Hartmann and Moosdorf, 2012) with an average scale of 1:3,750,000, therefore local to regional scale occurrences may be under-represented.

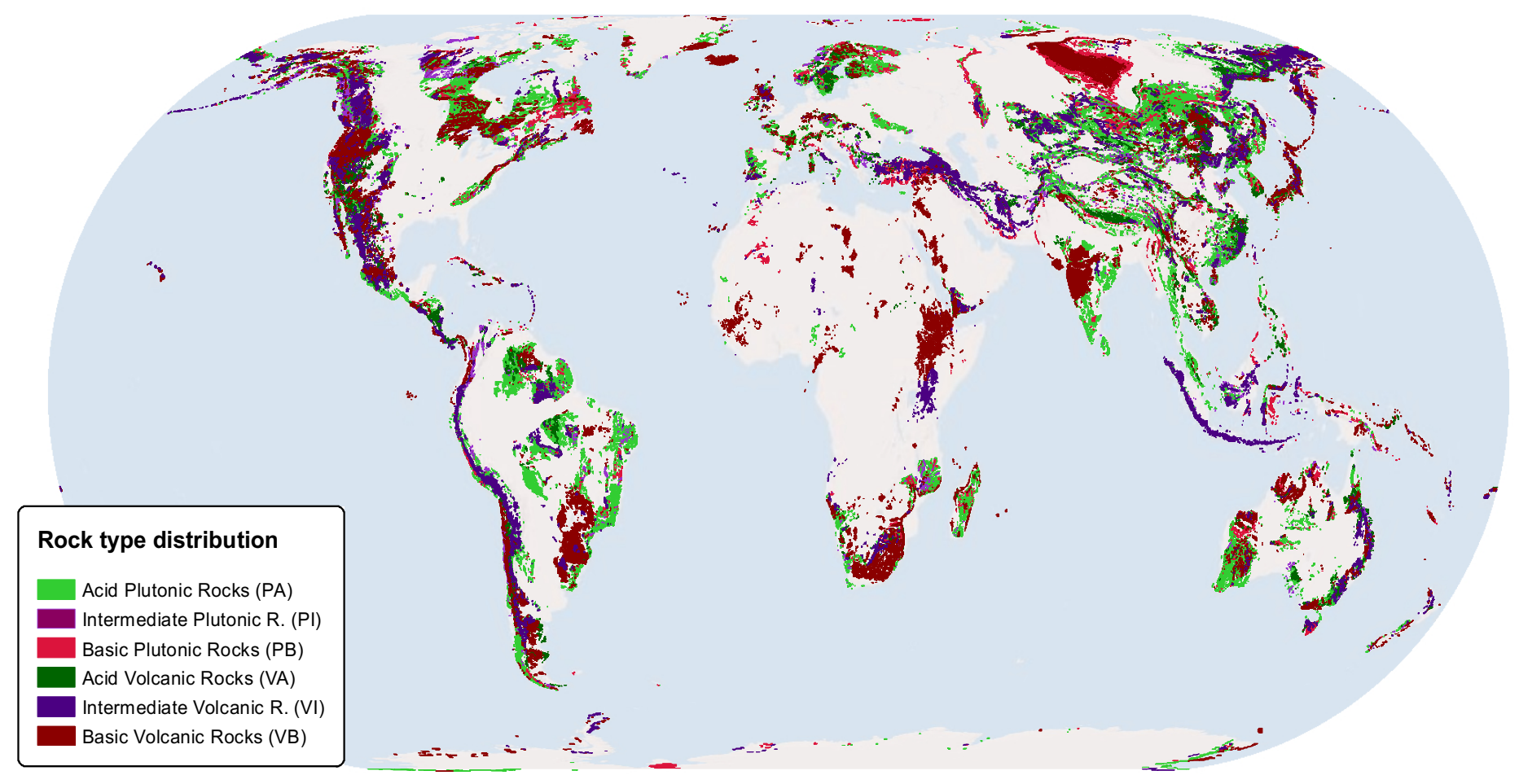

Tab. S5-1 Areal extents of the mapped rock classes

\begin{tabular}{rrr}
\hline $\begin{array}{r}\text { Rock } \\
\text { class }\end{array}$ & $\begin{array}{r}\text { Total } \\
\text { area } \\
{\left[10^{6} \mathrm{~km}^{2}\right]}\end{array}$ & $\begin{array}{r}\text { land } \\
\text { surface } \\
\text { cover } \\
{[\%]}\end{array}$ \\
\hline pa & 8.58 & $5,8 \%$ \\
pb & 1.03 & $0,7 \%$ \\
pi & 0.58 & $0,4 \%$ \\
va & 1.54 & $1,0 \%$ \\
vb & 5.25 & $3,5 \%$ \\
vi & 2.59 & $1,7 \%$ \\
\hline
\end{tabular}

Fig. S5-1 Global overview of the rock classes considered in this study. Data was extracted from the global lithological map database GLiM (Hartmann and Moosdorf, 2012). Coverage may appear larger than actual observations due to scaling effects for the figure. 


\section{S6. Calculation of element release rates}

To compare potential element release differences between rock classes based on their relative rate of weathering and the relative composition of rock geochemistry, bulk weathering rates for a well-studied humid subtropical region (the Japanese Archipelago) comparable to areas of likely application are chosen (Hartmann and Moosdorf, 2011; Hartmann et al., 2013). The Japanese Archipelago is in general characterized by high weathering capacity in comparison to humid tropical areas with depleted weathering profiles, where weathering rates can decrease by about 90\% (Hartmann et al., 2014). For catchments that were dominated by basic and intermediate volcanic rocks, a weathering rate of $33 \mathrm{t}$ base cations $+\mathrm{Si} \mathrm{km}^{-2} \mathrm{a}^{-1}$ was observed based on the analysis of nearly 400 catchments (Hartmann and Moosdorf, 2011). Field experiments with direct measurements of enhanced weathering rates due to finely ground rock product application, which would allow a more precise upscaling are still missing. The highest observed weathering rates of volcanic rocks including large areas of pyroclastics (comparable in some sense with EW) are about 3.5 times higher than rates calculated from Japanese catchments (Schopka et al., 2011). However, the temperature effect makes up for a about a factor of two alone if the temperature difference between Japan and the Philippines are considered. Data from the latter study consider also the significant contribution of waters with higher residence time than expected in top soil treated by rock powder, which affects the overall dissolution rate of total rock compartment including the soils (Maher, 2011).

The $\mathrm{P}$ and $\mathrm{K}$ release rate by enhanced chemical weathering is calculated assuming that $\mathrm{P}$ and $\mathrm{K}$ are released at the same relative rate as major cations and silicon are released via weathering, as a first order estimate (Hartmann and Moosdorf, 2011) for each considered rock type and its reported geochemical composition using the data from the GEOROC database (Suppl. S2). As $\mathrm{P}$ and $\mathrm{K}$ are preferentially taken up by the ecosystems the calculation, the assumptions are considered to be conservative, until field experimental data are available.

The first order upper boundary element release rate is calculated based on the major cation and silicon release rate and proportional to the total rock mass and assuming full dissolution as:

$$
\frac{W_{R}}{\sum(\% \text { Cations }+ \text { Si })_{\text {sample }}} \times c_{\text {element }}=\text { element release rate }\left[t \mathrm{~km}^{-2} \mathrm{a}^{-1}\right] \quad \text { Eq. S4-1 }
$$

With $W_{R}$ as the spatially explicit weathering rate (here $33 \mathrm{t}$ base cations and $\mathrm{Si} \mathrm{km}^{-2} \mathrm{a}^{-1}$ ) and $\%$ Cations as the rock specific values. This approach is suitable for geogenic nutrients like $\mathrm{P}$ and $\mathrm{K}$. Elemental solubility, $\mathrm{pH}$ and redox processes directly affect the release and retention of trace metals like $\mathrm{Cr}$ or $\mathrm{Ni}$, which is discussed separately. 


\section{S7. Rock class statistics}

Based on the procedure described in section S2, data for the figures of the main text were produced. A more detailed overview on the basic statistics of the specified geochemical rock classes and distinct rock types, for $\mathrm{Cr}, \mathrm{Ni}, \mathrm{P}$, and $\mathrm{K}$, is given below in Tabs. S7-1 - S7-4.

Tab. S7-1 Basic statistics of the data for chromium, extracted from the GEOROC database. All values given in ppm.

\begin{tabular}{|c|c|c|c|c|c|c|c|c|c|}
\hline & type & median & mean & std & $\min$ & $\max$ & $10 \%$ ile & $90 \%$ ile & $\mathrm{n}$ \\
\hline & basalt & 140 & 226 & 340 & 0 & 21,509 & 19 & 475 & 49,942 \\
\hline & dunite & 2,651 & 3,596 & 6,874 & 49 & 80,354 & 1,350 & 5,070 & 137 \\
\hline \multirow{4}{*}{$\begin{array}{l}\frac{0}{\frac{N}{T}} \\
\frac{\mathcal{U}}{O}\end{array}$} & ultrab. & 374 & 713 & 938 & 0 & 21,509 & 50 & 1,867 & 12,932 \\
\hline & basic & 180 & 326 & 528 & 0 & 11,000 & 24 & 687 & 48,681 \\
\hline & Interm. & 45 & 116 & 236 & 0 & 7,301 & 5 & 275 & 37,907 \\
\hline & acid & 8 & 33 & 153 & 0 & 7,018 & 0 & 64 & 18,669 \\
\hline \multirow{4}{*}{$\begin{array}{l}\frac{0}{2} \\
\frac{0}{J} \\
\frac{1}{2}\end{array}$} & ultrab. & 194 & 1,046 & 3,460 & 0 & 109,303 & 3 & 2,850 & 3,216 \\
\hline & basic & 159 & 423 & 779 & 0 & 17,745 & 17 & 1090 & 4,885 \\
\hline & Interm. & 47 & 166 & 424 & 0 & $7,, 345$ & 3 & 389 & 3,020 \\
\hline & acid & 13 & 37 & 137 & 0 & 4,621 & 0 & 88 & 2,969 \\
\hline
\end{tabular}

Tab. S7-2 Basic statistics of the data for nickel, extracted from the GEOROC database. All values given in ppm.

\begin{tabular}{|c|c|c|c|c|c|c|c|c|c|}
\hline & type & median & mean & std & $\min$ & $\max$ & 10\%ile & $90 \%$ ile & $\mathrm{n}$ \\
\hline & basalt & 74 & 110 & 151 & 0 & 8,550 & 13 & 231 & 52,091 \\
\hline & dunite & 2,129 & 2,985 & 5,743 & 320 & 50,669 & 916 & 3,354 & 236 \\
\hline \multirow{4}{*}{$\begin{array}{l}\frac{0}{\mathbb{E}} \\
\frac{\mathbb{N}}{O} \\
\frac{\mathcal{O}}{O}\end{array}$} & ultrab. & 227 & 462 & 693 & 0 & 24,591 & 44 & 1,256 & 13,471 \\
\hline & basic & 89 & 161 & 393 & 0 & 55,743 & 20 & 299 & 50,652 \\
\hline & Interm. & 24 & 51 & 121 & 0 & 7,900 & 3 & 118 & 39,830 \\
\hline & acid & 5 & 13 & 35 & 0 & 1,734 & 0 & 29 & 18,324 \\
\hline \multirow{4}{*}{$\begin{array}{l}\frac{0}{\frac{0}{\sigma}} \\
\frac{1}{2}\end{array}$} & ultrab. & 157 & 600 & 920 & 0 & 14,182 & 6 & 1,966 & 3,331 \\
\hline & basic & 91 & 192 & 365 & 0 & 8,667 & 18 & 410 & 5,043 \\
\hline & Interm. & 24 & 59 & 110 & 0 & $2,, 031$ & 2 & 146 & 3,118 \\
\hline & acid & 6 & 15 & 53 & 0 & 1171 & 0 & 29 & 3,355 \\
\hline
\end{tabular}

Tab. S7-3 Basic statistics of the data for potassium, extracted from the GEOROC database. All values given in ppm.

\begin{tabular}{|c|c|c|c|c|c|c|c|c|c|}
\hline & type & median & mean & std & $\min$ & $\max$ & $10 \%$ ile & $90 \%$ ile & $\mathrm{n}$ \\
\hline & basalt & 7,803 & 9,440 & 7,982 & 0 & 456,581 & 1,826 & 18,429 & 68,846 \\
\hline & dunite & 83 & 898 & 7,139 & 0 & 95,384 & 0 & 830 & 184 \\
\hline \multirow{4}{*}{ 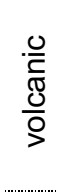 } & ultrab. & 9,381 & 11,333 & 10,673 & 0 & 86,335 & 772 & 22,082 & 20,697 \\
\hline & basic & 6,724 & 9,920 & 11,332 & 0 & 340,360 & 1,245 & 20,090 & 70,155 \\
\hline & Interm. & 13,531 & 18,590 & 16,262 & 0 & 456,581 & 4,317 & 43,085 & 59,515 \\
\hline & acid & 30,451 & 29,966 & 13,656 & 0 & 123,858 & 12,120 & 45,492 & 32,785 \\
\hline \multirow{4}{*}{$\begin{array}{l}\frac{0}{\frac{0}{2}} \\
\frac{0}{2} \\
\frac{3}{2}\end{array}$} & ultrab. & 2,158 & 7,382 & 11,117 & 0 & 148,513 & 83 & 22,165 & 4,774 \\
\hline & basic & 4,898 & 9,326 & 12,234 & 0 & 102,938 & 664 & 24,157 & 6,471 \\
\hline & Interm. & 16,686 & 22,249 & 18,570 & 0 & 152,830 & 3,819 & 47,650 & 4,680 \\
\hline & acid & 31,463 & 30,257 & 12,814 & 0 & 128,175 & 13,282 & 44,662 & 6,207 \\
\hline
\end{tabular}


Tab. S7-4 Basic statistics of the data for phosphorus, extracted from the GEOROC database. All values given in ppm.

\begin{tabular}{|c|c|c|c|c|c|c|c|c|c|}
\hline & type & median & mean & std & $\min$ & $\max$ & $10 \%$ ile & $90 \%$ ile & $\mathrm{n}$ \\
\hline & basalt & 1,309 & 1,609 & 1,248 & 0 & 31,728 & 428 & 3,186 & 65,363 \\
\hline & dunite & 52 & 476 & 4,560 & 0 & 59,702 & 0 & 305 & 171 \\
\hline \multirow{4}{*}{ 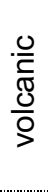 } & ultrab. & 2,589 & 2,982 & 3,827 & 0 & 366,594 & 436 & 5,412 & 20,298 \\
\hline & basic & 1,309 & 1,654 & 1,344 & 0 & 24,309 & 367 & 3,360 & 67,737 \\
\hline & Interm. & 916 & 1,173 & 978 & 0 & 39,540 & 393 & 2,226 & 56,786 \\
\hline & acid & 393 & 493 & 504 & 0 & 18,286 & 75 & 1,004 & 31,195 \\
\hline \multirow{4}{*}{ 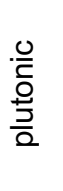 } & ultrab. & 969 & 4,482 & 11,252 & 0 & 238,591 & 44 & 11,434 & 4,655 \\
\hline & basic & 698 & 1,260 & 2,356 & 0 & 139,655 & 105 & 3,055 & 6,254 \\
\hline & Interm. & 890 & 1,229 & 1,201 & 0 & 26,185 & 262 & 2,619 & 4,461 \\
\hline & acid & 428 & 500 & 504 & 0 & 19,639 & 87 & 960 & 5,876 \\
\hline
\end{tabular}




\section{References}

Batal, A. B., Dale, N. M., and Saha, U. K.: Mineral composition of corn and soybean meal, The Journal of Applied Poultry Research, 19, 361-364, 10.3382/japr.2010-00206, 2010.

Belitz, H.-D.: Food chemistry, Fourth ed., edited by: Grosch, W., and Schieberle, P., Springer, Berlin u.a., 2009.

Brosse, N., Dufour, A., Meng, X., Sun, Q., and Ragauskas, A.: Miscanthus: a fast-growing crop for biofuels and chemicals production, Biofuels, Bioproducts and Biorefining, 6, 580-598, 10.1002/bbb.1353, 2012.

Erbs, M., Manderscheid, R., Jansen, G., Seddig, S., Pacholski, A., and Weigel, H.-J.: Effects of free-air $\mathrm{CO} 2$ enrichment and nitrogen supply on grain quality parameters and elemental composition of wheat and barley grown in a crop rotation, Agriculture, Ecosystems \& Environment, 136, 59-68, 10.1016/j.agee.2009.11.009, 2010.

Fageria, N. K.: Growth and mineral nutrition of field crops, Books in soils, plants, and the environment, edited by: Baligar, V. C., and Jones, C. A., Dekker, New York u.a., 1991.

FAOSTAT: Crops (National Production): http://www.fao.org/data/en/, access: 2017-31-05, 2017.

Hartmann, J., and Moosdorf, N.: Chemical weathering rates of silicate-dominated lithological classes and associated liberation rates of phosphorus on the Japanese Archipelago-Implications for global scale analysis, Chemical Geology, 287, 125-157, 10.1016/j.chemgeo.2010.12.004, 2011.

Hartmann, J., and Moosdorf, N.: The new global lithological map database GLiM: A representation of rock properties at the Earth surface, Geochem Geophy Geosy, 13, 10.1029/2012gc004370, 2012.

Hartmann, J., West, A. J., Renforth, P., Köhler, P., De La Rocha, C. L., Wolf-Gladrow, D. A., Dürr, H. $\mathrm{H}$., and Scheffran, J.: Enhanced chemical weathering as a geoengineering strategy to reduce atmospheric carbon dioxide, supply nutrients, and mitigate ocean acidification, Rev Geophys, 51, 113149, 10.1002/Rog.20004, 2013.

Hartmann, J., Moosdorf, N., Lauerwald, R., Hinderer, M., and West, A. J.: Global chemical weathering and associated P-release - The role of lithology, temperature and soil properties, Chemical Geology, 363, 145-163, 10.1016/j.chemgeo.2013.10.025, 2014.

Jasinski, M.: Minerals Yearbook: Volume I.-- Metals and Minerals, U.S. Geological Survey, 2017.

Maher, K.: The role of fluid residence time and topographic scales in determining chemical fluxes from landscapes, Earth and Planetary Science Letters, 312, 48-58, 10.1016/j.epsl.2011.09.040, 2011.

Manning, D. A. C.: How will minerals feed the world in 2050?, Proceedings of the Geologists' Association, 126, 14-17, 10.1016/j.pgeola.2014.12.005, 2015.

Moosdorf, N., Renforth, P., and Hartmann, J.: Carbon dioxide efficiency of terrestrial enhanced weathering, Environ Sci Technol, 48, 4809-4816, 10.1021/es4052022, 2014.

Renforth, P., Jenkins, B. G., and Kruger, T.: Engineering challenges of ocean liming, Energy, 60, $442-$ 452, 10.1016/j.energy.2013.08.006, 2013.

Schopka, H. H., Derry, L. A., and Arcilla, C. A.: Chemical weathering, river geochemistry and atmospheric carbon fluxes from volcanic and ultramafic regions on Luzon Island, the Philippines, Geochim Cosmochim Ac, 75, 978-1002, 10.1016/j.gca.2010.11.014, 2011. 